\title{
Guilty pleasures II: Restrained eaters' implicit preferences for high, moderate and low-caloric food
}

Citation for published version (APA):

Houben, K., Roefs, A., \& Jansen, A. (2012). Guilty pleasures II: Restrained eaters' implicit preferences for high, moderate and low-caloric food. Eating Behaviors, 13(3), 275-277.

https://doi.org/10.1016/j.eatbeh.2012.03.007

Document status and date:

Published: 01/08/2012

DOI:

10.1016/j.eatbeh.2012.03.007

Document Version:

Publisher's PDF, also known as Version of record

Document license:

Taverne

Please check the document version of this publication:

- A submitted manuscript is the version of the article upon submission and before peer-review. There can be important differences between the submitted version and the official published version of record.

People interested in the research are advised to contact the author for the final version of the publication, or visit the DOI to the publisher's website.

- The final author version and the galley proof are versions of the publication after peer review.

- The final published version features the final layout of the paper including the volume, issue and page numbers.

Link to publication

\footnotetext{
General rights rights.

- You may freely distribute the URL identifying the publication in the public portal. please follow below link for the End User Agreement:

www.umlib.nl/taverne-license

Take down policy

If you believe that this document breaches copyright please contact us at:

repository@maastrichtuniversity.nl

providing details and we will investigate your claim.
}

Copyright and moral rights for the publications made accessible in the public portal are retained by the authors and/or other copyright owners and it is a condition of accessing publications that users recognise and abide by the legal requirements associated with these

- Users may download and print one copy of any publication from the public portal for the purpose of private study or research.

- You may not further distribute the material or use it for any profit-making activity or commercial gain

If the publication is distributed under the terms of Article $25 \mathrm{fa}$ of the Dutch Copyright Act, indicated by the "Taverne" license above, 


\title{
Guilty pleasures II: Restrained eaters' implicit preferences for high, moderate and low-caloric food
}

\author{
Katrijn Houben *, Anne Roefs, Anita Jansen \\ Maastricht University, The Netherlands
}

\section{A R T I C L E I N F O}

\section{Article history:}

Received 9 November 2011

Received in revised form 13 March 2012

Accepted 23 March 2012

Available online 30 March 2012

\section{Keywords:}

Restrained eating

Dieting

Implicit attitudes

Indirect measures

Implicit Association Test (IAT)

\begin{abstract}
A B S T R A C T
In a previous study, restrained eaters showed stronger implicit preferences for high-caloric food compared to unrestrained eaters. Caloric density and palatability are however almost always intertwined, and it was never tested whether this high-calorie food preference of restrained eaters follows from the energy density or the palatability of high-calorie foods. Here, it was examined whether restrained eaters may hold stronger implicit preferences than unrestrained eaters for palatable food in general, irrespective of caloric density. Participants were randomly assigned to one of three conditions: Using two unipolar SCIATs positive and negative implicit associations were measured with palatable food of either high, moderate, or low caloric density. Results showed a strong effect of dietary restraint on implicit food preferences independently of caloric density, indicating stronger implicit preferences for all types of palatable food with increased dietary restraint. With respect to negative implicit associations, participants showed stronger negative implicit associations with high-calorie food than with moderate-calorie or low-calorie food, regardless of dietary restraint. Thus, restrained eaters show enhanced implicit preferences, not only for high caloric food, but for palatable food in general compared to unrestrained eaters.
\end{abstract}

(C) 2012 Elsevier Ltd. All rights reserved.

\section{Introduction}

Dietary restraint, which is the chronic limitation of food intake in order to lose weight, paradoxically seems to be characterized by frequent lapses of restraint and overconsumption (e.g., Fedoroff, Polivy, \& Herman, 1997; Harris, Bargh, \& Brownell, 2009; Herman \& Polivy, 1980; Jansen \& van den Hout, 1991). According to dualprocess models (e.g., Strack \& Deutsch, 2004), the reason for these counterproductive effects is that restrained eaters experience a tugof-war between motivational impulses to consume high-caloric palatable foods, and goals related to weight control. Specifically, palatable food may be automatically (implicitly) associated with positive affect in restrained eaters, thereby triggering the motivational impulse to indulge, even though they do not wish this to happen. Support for this intuitive assumption that dietary restraint is associated with stronger positive implicit associations with palatable high-caloric food, however, is mixed. While there is evidence showing stronger positive implicit associations with high-caloric food in restrained eaters compared to unrestrained eaters (e.g., Hoefling \& Strack, 2008), other studies have found no relationship (e.g., Roefs, Herman, MacLeod, Smulders, \& Jansen, 2005), or even a negative relationship between dietary restraint and implicit positive associations with high-caloric food

\footnotetext{
* Corresponding author at: Clinical Psychological Science, Maastricht University, PO BOX 616, 6200 MD Maastricht, The Netherlands. Tel.: +31 433881953; fax: + 31 433884196

E-mail address: K.Houben@maastrichtuniversity.nl (K. Houben).
}

(e.g., Maison, Greenwald, \& Bruin, 2001; Papies, Stroebe, \& Aarts, 2009; Vartanian, Polivy, \& Herman, 2004).

Most previous studies, however, examined differences between restrained and unrestrained eaters regarding their implicit associations with high-caloric food relative to low-caloric food. Consequently, it is unclear whether these findings reflect implicit attitudes toward high-caloric food or toward low-caloric food. Recently, we demonstrated that restrained eaters do not associate high-caloric food more strongly with positive affect compared to low-caloric food (Houben, Roefs, \& Jansen, 2010). However, when we measured implicit positive associations with high-caloric food without the low-caloric food contrast, restrained eaters did show such positive associations, and also associated high-caloric food more strongly with positive affect compared to unrestrained eaters. One explanation for these findings could be that restrained eaters associate both high-caloric and low-caloric food more strongly with positive affect than unrestrained eaters. Is there any evidence to suggest that restrained eaters may hold a preference for food irrespective of caloric density?

While most previous research focused mainly on the effect of exposure to palatable, high-caloric food cues on subsequent consumption (e.g., Fedoroff et al., 1997; Jansen \& van den Hout, 1991), there is at least some evidence suggesting that exposure to palatable food increases consumption in restrained eaters regardless of caloric density (Harris et al., 2009). Thus, restrained eaters may experience stronger impulses to consume any type of palatable food, irrespective of caloric density. This study further examined this issue. Specifically, we 
measured positive and negative implicit associations with palatable food of either high, moderate, or low caloric density using unipolar SCIATs. We expected that dietary restraint would be associated with stronger implicit preferences toward all types of food, regardless of caloric density. Based on our previous findings (Houben et al., 2010), we further expected no differences between restrained and unrestrained eaters with respect to implicit negative associations with the different types of food.

\section{Method}

\subsection{Participants}

Participants were 112 female volunteers (age: $M=24.88$, $S D=5.92 ;$ BMI [Body Mass Index; $\mathrm{kg} / \mathrm{m}^{2}$ ]: $M=23.50, S D=4.20$, range 18.03-40.56) who completed this study in return for a gift certificate.

\subsection{Measures and procedure}

Participants were recruited and tested via the Internet. After giving consent, participants were randomly assigned to one of the three conditions: A high-caloric food (HC) condition, a moderate-caloric food (MC) condition, and a low-caloric food (LC) condition. In all three conditions, participants then performed a unipolar positive Single Category Implicit Association Test (SCIAT; Karpinski \& Steinman, 2006; see also Houben et al., 2010) and a unipolar negative SCIAT, in balanced order.

Both SCIATs consisted of three blocks. In block 1 (24 trials), participants sorted stimuli into two attribute concepts using two response keys. In the unipolar positive SCIAT, participants sorted stimuli as pleasant (tasty, delicious, good, delightful, heavenly, outstanding) or neutral (average, undefined, general, normal, usual, everyday). In the unipolar negative SCIAT, participants sorted stimuli as unpleasant (tasteless, unsavoury, bad, nasty, awful, disgusting) or neutral. In block 2 (72 trials), participants sorted stimuli of one attribute category and the food target category with one response key, and items from the other attribute category with the other key (e.g., [un]pleasant + food vs. neutral). The target category consisted of six pictures of high-caloric food (i.e., $>3 \mathrm{kcal} / \mathrm{g}$; e.g., French fries, pizza) in the HC condition, six pictures of moderatecaloric food (i.e., 1.0-3.0 kcal/g; e.g., steak, cooked potatoes) in the MC condition, and six pictures of low-caloric food (i.e., $<1.0 \mathrm{kcal} / \mathrm{g}$; e.g., salad, fruits) in the LC condition. In block 3 (72 trials), the response assignment of the food target category was reversed and participants performed the reversed combination (e.g., [un]pleasant vs. neutral + food). To keep the number of left and right responses comparable in block 2 and in block 3, food-related pictures were presented 30 times, attributes assigned to the same response key as food were presented 12 times, and attributes assigned to the other response key were presented 30 times. The response assignment of the target and attribute categories was counterbalanced across participants. Stimuli were presented in the middle of the computer screen and the labels of the categories assigned to the left and right response key were presented in the corresponding upper corners of the screen.

Next, participants rated the food pictures that were presented during the SCIATs (i.e., high, moderate, or low-caloric food, depending on the condition) on caloric density (7-point Likert scale: $1=$ low caloric density, $7=$ high caloric density) and on palatability (7-point Likert scale: $1=$ unpalatable, $7=$ palatable). Next, participants filled out the Restraint Scale (RS; Herman \& Polivy, 1980), consisting of 10 items assessing dietary restraint. Higher scores indicate an increased intention to restrict food intake. Finally, participants reported their weight and height (used to calculate BMI).

\section{Results}

\subsection{Manipulation check}

Mean caloric density ratings were analyzed using a Univariate Analysis of Variance (ANOVA) with condition (HC, MC or LC) as a between-subjects factor and dietary restraint as a (standardized) continuous covariate (instead of performing a median split to minimize loss of power, van Breukelen \& van Dijk, 2007). Means for high and low dietary restraint are estimated at $-1 S D$ and $+1 S D$, respectively. The mean restraint score was $14.63(S D=5.87)$. Results showed a significant effect of condition, $F(2,106)=133.48, p<.001$, while the effect of restraint, $F(1,106)=1.46, p=.23$, nor its interaction with condition $(F<1)$ was significant. Follow-up t-tests indicated that the high-caloric food in the $\mathrm{HC}$ condition was perceived as richer in calories $(M=6.20, S D=.59)$ compared to the moderate-caloric food in the MC condition $(M=4.09, S D=.83), t(70)=12.50, p<.001$, and that the moderate-caloric food in the MC condition was judged as higher in calories than the low-caloric food in the LC condition $(M=2.45$, $S D=1.01), t(72)=7.58, p<.001$.

Similarly, mean palatability ratings were analyzed using ANOVA with condition (HC, MC or LC) as a between-subjects factor and dietary restraint as a (standardized) continuous covariate. Results showed a significant effect of condition, $F(2,106)=5.69, p=.005$, while neither the effect of restraint or its interaction with condition (both $F<1$ ) was significant. Follow-up t-tests indicated that the high caloric food in the HC condition was perceived as equally palatable $(M=4.74, S D=.93)$ as the moderate-caloric food in the MC condition $(M=4.59, S D=.88), t(70)=.72, p=.48$. However, the low-caloric food in the LC condition was rated higher in palatability $(M=5.33$, $S D=.97)$ than the moderate-caloric food in the MC condition, $t(72)=$ $3.42, p=.001$.

\subsection{Implicit attitudes}

For both the positive and negative SCIAT, scores were calculated with the D600 scoring algorithm (Greenwald, Nosek, \& Banaji, 2003) so that higher scores respectively indicate stronger positive or stronger negative associations with food. Positive and negative SCIAT scores were analyzed separately using ANOVA with condition (i.e., HC, MC, or LC) as a between-subjects factor and dietary restraint as a (standardized) continuous covariate. Because one participant did not complete the positive SCIAT, the analysis on positive SCIAT effects was conducted with 111 participants.

Results for the positive SCIAT showed no significant effect of condition $(F<1)$. Overall, participants had positive implicit associations with high-caloric food, $t(37)=5.10, p<.001$, moderate-caloric food, $t(32)=4.00, p<.001$, and low-caloric food, $t(39)=5.13, p<.001$. While the interaction between dietary restraint and condition was not significant $(F<1)$, results did show a significant effect of dietary restraint, $F(1,105)=6.21, p=.01$, indicating that restrained eaters had stronger positive implicit associations with food than unrestrained eaters, regardless of caloric density (see Fig. 1).

Results for the negative SCIAT showed no significant effect of dietary restraint or its interaction with condition (both $F<1$ ), while the effect of condition was marginally significant, $F(2,106)=2.65$, $p=.08$. Follow-up t-tests confirmed that participants associated high-caloric food more strongly with negative affect than lowcaloric food, $t(76)=2.41, p=.02$ (see Fig. 2). There was no significant difference in negative implicit associations between high-caloric and moderate-caloric food, $t(70)=.45, p=.66$, or between moderate and low-caloric food, $t(72)=1.69, p=.10$. One-sample t-tests further showed that participants associated high-caloric food with negative affect, $t(37)=2.74, p=.01$, while they did not associate moderate, $t(33)=1.52, p=.14$, or low-caloric food, $t(39)=.81, p=.43$, with negative affect. 


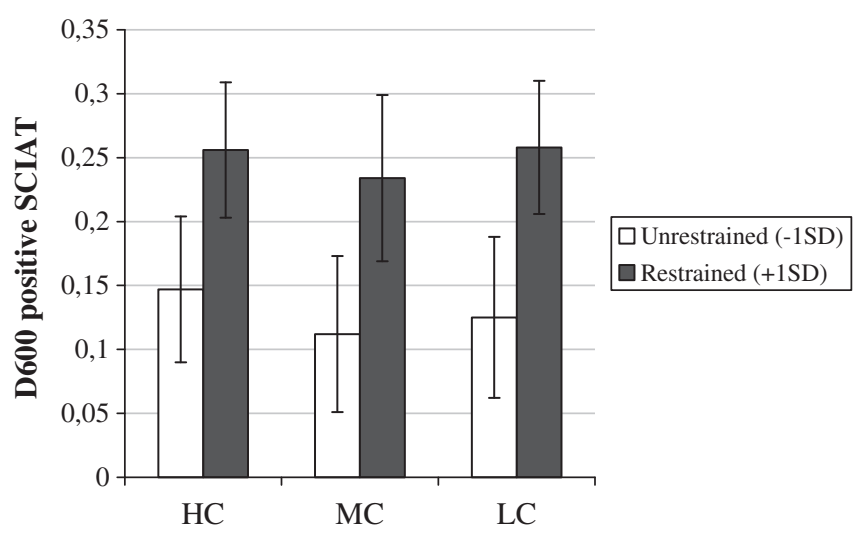

Fig. 1. Mean effects (with standard errors) for the positive unipolar SCIAT (D600 effect measure) in restrained versus unrestrained eaters (respectively $1 S D$ above or below mean RS score). Higher D600 scores indicate stronger implicit positive associations with high-caloric (HC), moderate-caloric (MC) or low-caloric (LC) food.

\section{Discussion}

The aim of this research was to examine whether dietary restraint is related to stronger positive implicit attitudes toward palatable food of low, moderate and high caloric density. To test this hypothesis, two unipolar SCIATs were used to measure implicit positive and negative associations with palatable food of high, moderate, or low caloric density. As expected, restrained eaters demonstrated stronger implicit positive associations with palatable food, irrespective of caloric density. Thus, restrained eaters not only hold stronger implicit preferences for palatable high-caloric food as demonstrated in our previous study (Houben et al., 2010), but that they also hold stronger positive implicit attitudes toward palatable food with moderate and low caloric density. In addition, we did not find an effect of dietary restraint on implicit negative associations with food, which is similar to our previous findings (Houben et al., 2010).

Together, these findings suggest that restrained eaters, compared to unrestrained eaters, have stronger implicit positive associations with palatable food in general. Restrained eaters, thus, seem to experience a conflict between their goal of weight control and food restriction (reflective system), and strong positive implicit attitudes toward palatable

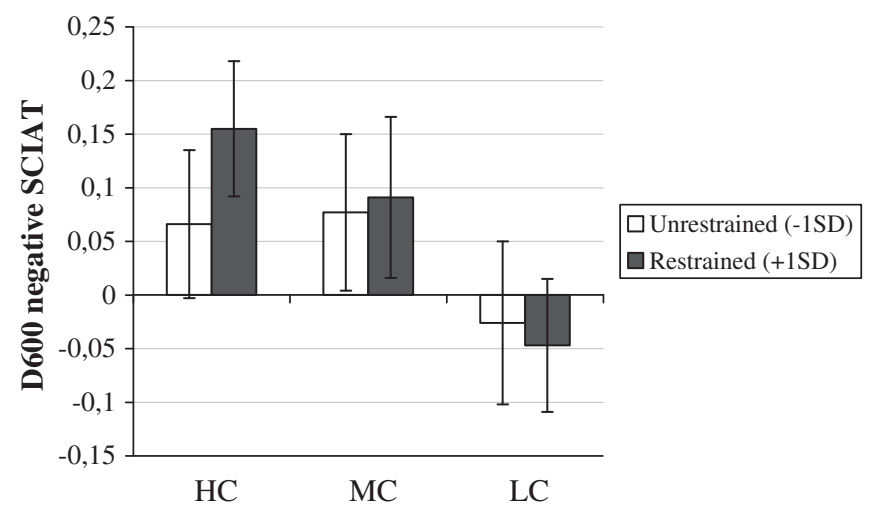

Fig. 2. Mean effects (with standard errors) for the negative unipolar SCIAT (D600 effect measure) in restrained versus unrestrained eaters (respectively $1 S D$ above or below mean RS score). Higher D600 scores indicate stronger implicit negative associations with high-caloric (HC), moderate-caloric (MC) or low-caloric (LC) food. food causing a strong behavioral disposition to overconsume palatable food (impulsive system). Whenever such conflicts arise between the motivational drive to overeat and personal goals such as dieting standards, the motivational drive needs to be overruled by higher-order inhibitory control processes, so that behavior is more in line with deliberate long-term goals (Strack \& Deutsch, 2004). Consequently, when inhibitory control is somehow impaired, the motivational drive will be more dominant in guiding eating behavior, leaving one unable to resist the temptations of palatable food (Friese, Hofmann, \& Wänke, 2008; Hofmann, Rauch, \& Gawronski, 2007; Houben \& Jansen, 2011).

The present findings suggest that the impulsive system generates a stronger signal to overeat in restrained eaters compared to unrestrained eaters due to their stronger positive implicit attitudes toward food. Restrained eaters therefore need to expend more cognitive resources to inhibit this automatic impulse. However, restrained eaters also appear to be less able to exert inhibitory control compared to unrestrained eaters (Nederkoorn, Van Eijs, \& Jansen, 2004). Consequently, automatic impulses more easily gain the upper hand in restrained eaters, causing lapses of restraint and overconsumption.

\section{Role of funding sources}

Funding for this study was provided by a grant from the Technology Foundation STW; the sponsors had no further role in study design; in the collection, analysis and interpretation of data; in the writing of the report; or in the decision to submit the paper for publication.

\section{Contributors}

Katrijn Houben designed the study. Katrijn Houben performed the statistical analysis, and wrote the first draft of the manuscript. All authors contributed to and have approved the final manuscript.

\section{Conflict of interest}

All other authors declare that they have no conflicts of interest.

\section{References}

Fedoroff, I. C., Polivy, J., \& Herman, C. P. (1997). The effect of pre-exposure to food cues on the eating behaviour of restrained and unrestrained eaters. Appetite, 28, 33-47.

Friese, M., Hofmann, W., \& Wänke, M. (2008). When impulses take over: Moderated predictive validity of explicit and implicit attitude measures in predicting food choice and consumption behaviour. British Journal of Social Psychology, 47, 397-419.

Greenwald, A. G., Nosek, B. A., \& Banaji, M. R. (2003). Understanding and using the implicit association test: I. An improved scoring algorithm. Journal of Personality and Social Psychology, 85, 197-216.

Harris, J. L., Bargh, J. A., \& Brownell, K. D. (2009). Priming effects of television food advertising on eating behavior. Health Psychology, 28, 404-413.

Herman, C. P., \& Polivy, J. (1980). Restrained eating. In A. J. Stunkard (Ed.), Obesity (pp. 208-225). Philadelphia: Saunders.

Hoefling, A., \& Strack, F. (2008). The tempting effect of forbidden foods: High calorie content evokes conflicting implicit and explicit evaluations in restrained eaters. Appetite, 51, 681-689.

Hofmann, W., Rauch, W., \& Gawronski, B. (2007). And deplete us not into temptation: Automatic attitudes, dietary restraint, and self-regulatory resources as determinants of eating behavior. Journal of Experimental Social Psychology, 43, 497-504.

Houben, K., \& Jansen, A. (2011). Training inhibitory control: A recipe for resisting sweet temptations. Appetite, 56, 345-349.

Houben, K., Roefs, A., \& Jansen, A. (2010). Guilty pleasures: Implicit preferences for high calorie food in restrained eating. Appetite, 55, 18-24.

Jansen, A., \& van den Hout, M. A. (1991). On being led into temptation: "Counterregulation" of dieters after smelling a "preload". Addictive Behaviors, 16, 247-253.

Karpinski, A., \& Steinman, R. B. (2006). The Single-Category Implicit Association Test as a measure of implicit social cognition. Journal of Personality and Social Psychology, $91,16-32$.

Maison, D., Greenwald, A. G., \& Bruin, R. (2001). The Implicit Association Test as a measure of implicit consumer attitudes. Polish Psychological Bulletin, 32, 61-69.

Nederkoorn, C., Van Eijs, Y., \& Jansen, A. (2004). Restrained eaters act on impulse. Personality and Individual Differences, 37, 1651-1658.

Papies, E. K., Stroebe, W., \& Aarts, H. (2009). Who likes it more? Restrained eaters' implicit attitudes towards food. Appetite, 53, 279-287.

Roefs, A., Herman, C. P., MacLeod, C. M., Smulders, F. T. Y., \& Jansen, A. (2005). At first sight: How do restrained eaters respond to high-fat palatable foods? Appetite, 44, 103-114.

Strack, F., \& Deutsch, R. (2004). Reflective and impulsive determinants of social behavior. Personality and Social Psychology Review, 8, 220-247.

van Breukelen, G. J. P., \& van Dijk, K. R. A. (2007). Use of covariates in randomized controlled trials. Journal of the International Neuropsychological Society, 13, 903-904.

Vartanian, L. R., Polivy, J., \& Herman, C. P. (2004). Implicit cognitions and eating disorders: Their application in research and treatment. Cognitive and Behavioral Practice, 11, 160-167. 